complex nature of the tricuspid valve, subvalvular apparatus and RV. Even by the authors' own admission, however, this experimental model presents a simplified version of FTR pathology. An ex vivo model is not meant to serve as an in vivo surrogate, but rather functions to remove external variables to isolate the area of interest. The true value in this study, then, is in its validation of previous in vivo analyses suggesting a need to correct subvalvular pathology along with the valve itself. ${ }^{7,8}$

Ultimately, the true nature of severe FTR is one that necessitates careful consideration not only of the status of the right heart but the entire cardiovascular system and overall patient health. Indeed, while ideal surgical management of FTR may very well involve addressing both the valve and subvalvular apparatus, the Hippocratic dictum of primum non nocere may prevail and instead warrant a safe, if not optimal, valve-only approach. Overall, Amedi and colleagues are to be commended for their experimental ingenuity as well as their meaningful contribution to the understanding of the tricuspid valve and associated repair techniques. Through their findings, further proof is given to the assertion that addressing subvalvular pathology is necessary in finding a true gold standard repair for FTR.

\section{References}

1. Topilsky Y, Maltais S, Medina Inojosa J, Oguz D, Michelena H, Maalouf J, et al. Burden of tricuspid regurgitation in patients diagnosed in the community setting. JACC Cardiovasc Imaging. 2019;12:433-42.

2. Taramasso M, Vanermen H, Maisano F, Guidotti A, La Canna G, Alfieri O. The growing clinical importance of secondary tricuspid regurgitation. J Am Coll Cardiol. 2012;59:703-10.

3. Zack CJ, Fender EA, Chandrashekar P, Reddy YNV, Bennett CE, Stulak JM, et al. National trends and outcomes in isolated tricuspid valve surgery. J Am Coll Cardiol. 2017;70:2953-60.

4. Fukuda S, Gillinov AM, McCarthy PM, Stewart WJ, Song JM, Kihara T, et al. Determinants of recurrent or residual functional tricuspid regurgitation after tricuspid annuloplasty. Circulation. 2006;114(1 suppl):I582-7.

5. Fukunaga N, Okada Y, Konishi Y, Murashita T, Koyama T. Late outcome of tricuspid annuloplasty using a flexible band/ring for functional tricuspid regurgitation. Circ J. 2015;79:1299-306.

6. Amedi A, Onohara D, Xu D, Suresh KS, Padala M. Hemodynamic outcomes after undersizing ring annulplasty and focal suture annuloplasty for surgical repair of functional tricuspid regurgitation. J Thorac Cardiovasc Surg. 2022;164:76-87.e1.

7. Ouda A, Matschke K, Ghazy T, Speiser U, Alexiou K, Tugtekin SM, et al. Right ventricular reduction for repair of functional tricuspid valve regurgitation: oneyear follow up. J Heart Valve Dis. 2013;22:754-61.

8. Jazwiec T, Malinowski M, Ferguson H, Wodarek J, Quay N, Bush J, et al. Effect of variable annular reduction on functional tricuspid regurgitation and right ventricular dynamics in an ovine model of tachycardia-induced cardiomyopathy. $J$ Thorac Cardiovasc Surg. November 22, 2019 [Epub ahead of print].

\title{
Commentary: One ring to rule them all?
}

\author{
Asvin M. Ganapathi, MD, and \\ Nahush A. Mokadam, MD
}

J. R. R. Tolkien's Lord of the Rings trilogy has as its centerpiece the character of Gollum and his obsession with the One Ring to Rule Them All. The tale, which is epic and has spawned numerous literary and philosophical debates,

\footnotetext{
From the Division of Cardiac Surgery, Department of Surgery, The Ohio State University Wexner Medical Center, Columbus, Ohio.

Disclosures: Dr Mokadam is a consultant and investigator for Abbott, Medtronic, Carmat, and SynCardia. Dr Ganapathi has reported no conflicts of interest.

The Journal policy requires editors and reviewers to disclose conflicts of interest and to decline handling or reviewing manuscripts for which they may have a conflict of interest. The editors and reviewers of this article have no conflicts of interest.

Received for publication Sept 27, 2020; revisions received Sept 27, 2020; accepted for publication Sept 29, 2020; available ahead of print Oct 3, 2020.

Address for reprints: Asvin M. Ganapathi, MD, Division of Cardiac Surgery, The Ohio State University Wexner Medical Center, N-809 Doan Hall, 410 West 10th Ave, Columbus, OH 43210 (E-mail: Asvin.Ganapathi@osumc.edu).

J Thorac Cardiovasc Surg 2022;164:90-1

$0022-5223 / \$ 36.00$

Copyright (c) 2020 by The American Association for Thoracic Surgery

https://doi.org/10.1016/j.jtcvs.2020.09.118
}

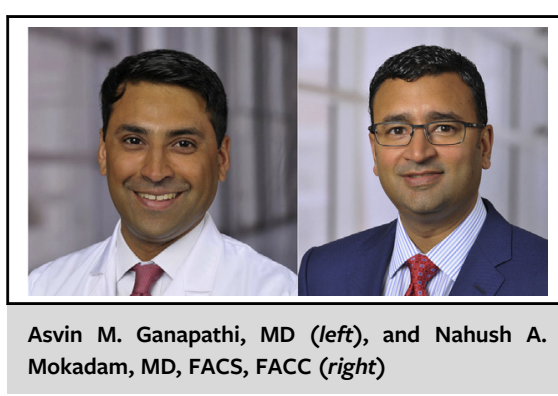

CENTRAL MESSAGE

Tricuspid valve ring annuloplasty

might not be the best interven-

tion for functional tricuspid valve

regurgitation. Understanding

mechanisms of failure may lead

to more durable repairs.

centers on the single ring that is all-powerful and designed to help Sauron gain control of Middle Earth. While there are numerous memorable characters and plots, Gollum calling 
the ring "my precious" is one of the most iconic aspects of the books and movies.

In this issue of the Journal, Amedi and colleagues ${ }^{1}$ describe their examination of 2 surgical techniques for tricuspid valve repair: tricuspid valve ring annuloplasty and Hetzer focal suture annuloplasty. They compare the 2 repair techniques using an ex vivo porcine heart functional model of tricuspid valve regurgitation (TR). Although both annuloplasty methods reduced functional TR, neither completely eliminated the TR, and the residual regurgitation was secondary to persistent leaflet tethering and decreased mobility. ${ }^{1}$ Although the data are not from in vivo human measurements, they provide valuable information about 2 current tricuspid repair techniques and more importantly helps to explain the potential failure mechanisms of these repairs. These data may also help to explain the reported rates of recurrence of significant TR in $6 \%$ to $31 \%$ of patients following tricuspid ring annuloplasty. ${ }^{2}$

Given that functional TR accounts for nearly $90 \%$ of all cases of TR, ${ }^{3}$ an understanding of the optimum method of repair is essential. Current guidelines for tricuspid valve repair are somewhat vague, with the only class 1 recommendation being for severe TR. ${ }^{4}$ However, there is evidence demonstrating a lack of improvement of functional TR when left alone, and persistent significant TR is known to be associated with decreased quality of life and survival. ${ }^{5}$

Given the lack of clear direction, some believe that addressing the primary pathology (ie, mitral or aortic insufficiency) will lead to resolution of significant TR. Furthermore, the primary method of repair is ring annuloplasty alone given its ease of performance, with some advocating for use of a certain ring size for almost all patients. ${ }^{6}$ This approach is quite different from the treatment of mitral valve regurgitation, for which there are numerous accepted options, although the most frequently used approaches are combinations of various techniques, such as chordal replacement or leaflet resection, with ring annuloplasty. Thus, models such as that described by Amedi and colleagues will help us understand why a particular method of repair may fail and potentially lead to more durable repair techniques.

As we continue to grapple with functional TR, a better understanding of the impact of our repairs will be crucial to advances in therapy, and it will be beneficial to consider methods beyond simple ring annuloplasty. We do not live in Middle Earth, and despite our desire to follow Gollum's lead, in tricuspid valve repair, we need to stop searching for the One Ring to Rule Us All.

\section{References}

1. Amedi A, Onohara D, Xu D, Sreerangathama Suresh K, Padala M. Hemodynamic outcomes after undersizing ring annuloplasty and focal suture annuloplasty for surgical repair of functional tricuspid regurgitation. J Thorac Cardiovasc Surg. 2022; 164:76-87.e1.

2. McCarthy PM, Sales VL. Evolving indications for tricuspid valve surgery. Curr Treat Options Cardiovasc Med. 2010;12:587-97.

3. Badano LP, Muraru D, Enriquez-Sarano M. Assessment of functional tricuspid regurgitation. Eur Heart J. 2013;34:1875-85.

4. Nishimura RA, Otto CM, Bonow RO, Carabello BA, Erwin JP 3rd, Guyton RA et al. 2014 AHA/ACC guideline for the management of patients with valvular heart disease: executive summary. A report of the American College of Cardiology/ American Heart Association Task Force on Practice Guidelines. Circulation. 2014:129:2440-92.

5. Taramasso M, Vanermen H, Maisano F, Guidotti A, La Canna G, Alfieri O. The growing clinical importance of secondary tricuspid regurgitation. J Am Coll Cardiol. 2012;59:703-10.

6. Huffman LC, Nelson JS, Lehman AN, Krajacic MC, Bolling SF. Identical tricuspid ring sizing in simultaneous functional tricuspid and mitral valve repair: a simple and effective strategy. J Thorac Cardiovasc Surg. 2014;147: 611-4. 